\title{
Bioimpedance and chronoamperometry as an adjunct to prostate-specific antigen screening for prostate cancer
}

This article was published in the following Dove Press journal:

Cancer Management and Research

19 April 201 I

Number of times this article has been viewed

\section{Darci Schiavon de Abreu \\ Department of Urology, Hospital Unimed de Limeira, Sao Paulo, Brazil}

Correspondence: Darci Schiavon de Abreu Rua Guararapes 95I, Vila Claudia, Limeira SP, CEP I 3 480-405 Brazil Tel +55(I9) 344I5409 Fax +55(I9) 3306-0308 Email d.schiavon@gmail.com
Background: Bioimpedance is an electrical property of living tissue that has been shown to be a safe technique when used in a number of biomedical applications. The aim of this research was to assess the utility of bioimpedance measurement as a rapid, cost-effective, and noninvasive adjunct to digital rectal examination and PSA in differentiating tumor from normal prostatic tissue.

Methods: Three hundred men were examined for signs and symptoms of prostate disorders. 147 patients with a digital rectal examination indicating a positive result underwent a prostatespecific antigen (PSA) test. A biopsy was advised for 103 of the men, of whom 50 completed the study. Before undergoing biopsy, an examination with the EIS (electro interstitial scan) system using bioimpedance and chronoamperometry was performed. In reference to the biopsy results (negative or positive), a statistical analysis of the EIS data and PSA was conducted using receiver operating characteristic curves to determine the specificity and sensitivity of each test.

Results: The PSA test had a sensitivity of $73.9 \%$ and specificity of $51.9 \%$ using a cutoff value $>4$ and a sensitivity of $52.2 \%$ and specificity of $81.5 \%$ using a cutoff value $\geq 5.7$ and $P=0.03$. The delta of the electrical conductivity (DE) of the left foot-right foot pathway had a sensitivity of $62.5 \%$ and specificity of $85.2 \%$, with a cutoff value $\leq-5$ and $P=0.0001$. Algorithms comprising the delta of electrical conductivity and PSA showed a sensitivity of $91.5 \%$ and a specificity of $59.3 \%$, with a cutoff value $\leq-10.52$ and $P=0.0003$.

Conclusion: The EIS system had a very good specificity of $85.2 \%$. However, the sensitivity of $62.5 \%$ would be a problem. Using a PSA reference $>4.1 \mathrm{ng} / \mathrm{mL}$, the adjunctive use of bioimpedance and chronoamperometry provided by EIS technology could raise the sensitivity from $73.9 \%$ to $91.5 \%$ and the specificity from $51.9 \%$ to $59.3 \%$ in prostate cancer screening.

Keywords: prostate cancer screening, bioimpedance, delta of conductivity, electro interstitial scan system

\section{Introduction}

In the US, prostate cancer is the most commonly diagnosed malignancy and the second leading cause of mortality from cancer in men. ${ }^{1}$ In 1997 , there were at least 209,900 new cases of prostate cancer diagnosed and more than 41,800 deaths from prostate cancer. ${ }^{2}$ At present, a transrectal ultrasound with prostatic biopsy is recommended in men with an abnormal digital rectal examination and/or an elevated prostate-specific antigen (PSA) level, and who are potential candidates for therapy.

According to the US Bureau of the Census in 1998, there were an estimated 30 million men in the US over the age of 50 years. ${ }^{3}$ A subset of this population represents those men who should undergo screening according to recommendations made by the American Urological Association. ${ }^{4}$ In a study by Arcangeli et al, ${ }^{6} 8 \%-15 \%$ of men 
screened were estimated to have an abnormal PSA test (ie, serum PSA $\geq 4.1 \mathrm{ng} / \mathrm{mL}$ by monoclonal assay) or had an abnormal digital rectal examination, half of whom had no identifiable pathology on biopsy. ${ }^{5} \mathrm{~A}$ further study has shown that about $66 \%$ of men with abnormally elevated PSA levels go on to have a negative biopsy, ${ }^{6}$ and another showed that $19 \%-32 \%$ of men who agreed to undergo biopsy were found to have prostate cancer. ${ }^{5}$ An indicator/marker adjunctive to the digital rectal examination and PSA would help the clinician in the decision to perform a biopsy.

Bioimpedance is an electrical property of living tissue that has been shown to be a safe technique when used in a number of biomedical applications, including for quantification of brain edema in neurosurgery ${ }^{7}$ and for differentiating between cancer and pneumonia on discovery of a pulmonary mass. ${ }^{8}$ Electric current is normally limited in living tissue by highly insulating cell membranes. However, the abnormal architecture in cancerous tissue may impede current differently and allow detection of differences between normal and abnormal or malignant prostate tissue. ${ }^{9}$

The aim of this research was to assess the utility of bioimpedance measurement as a rapid, cost-effective, and noninvasive adjunct to digital rectal examination and PSA in differentiating tumor from normal prostatic tissue.

One explanation as to why bioimpedance increases in cancer tissue is the distorted architecture of the gland, which prevents flow of current. Histologically, the prostate can be thought of as being composed of multiple layers of hollow glands (ie, tubes). Solid or gross tumor tissue is also composed of a histological array of tubes. The lumina in normal prostate tissue are open and have relatively large diameters, providing little resistance to flow. In contrast, as resistance increases, the current flow will decrease. Accordingly, in cancerous prostate tissue, the normal architecture of the lumina becomes distorted. The lumina of the tubes become much smaller, the walls of the glands become crowded, and the flow of current is impeded. ${ }^{9}$

The second explanation could be the electrochemical reaction in the anode related to the Chloride ions migration. The electrochemical reaction provides $4 \mathrm{H}+$ and is therefore an acid environment.

The pronounced elevations in prostatic tissue palmitoleic acid in cancer patients highlight a possible role of this fatty acid in neoplastic processes. ${ }^{10}$

We compared the results of PSA testing and biopsy with the results of EIS measurement to determine if the EIS system could be used as an adjunct to screening for prostate cancer.

\section{Materials and methods}

This study was approved by the regional ethic committee (Pesquisa CONEP, 125/10), and adhered to the ethical principles of the Declaration of Helsinki. Each patient signed an informed consent form, and confidentiality was maintained for all participants.

\section{Subjects}

Patients attending consultations for signs and/or symptoms of a prostatic disorder and not receiving any prostate treatment, as well as responders to an advertisement were considered for enrolment into this study. Inclusion criteria were a high PSA test result $(>4 \mathrm{ng} / \mathrm{mL})$ and/or a positive digital rectal examination with a clinical recommendation of prostate biopsy. Patients were excluded if they had previously undergone prostate-related chemotherapy or surgery, were currently receiving treatment for a prostatic disorder, had a neurological disorder precluding the ability to sign a consent form, if in the opinion of the investigator they were clinically unsuitable candidates for the trial, and/or had any contraindications to use of the EIS system. Use of the EIS system is contraindicated in the presence of an external defibrillator, skin lesions likely to come into contact with the electrodes, excessive perspiration, sinusitis (particularly frontal), cardiac pacemaker, electronic life support, any implanted electronic device, inability to remain still for three minutes, metallic pins or prostheses in digits or joints, pregnancy from the third trimester onwards, and absence of a limb.

Three hundred patients of mean age 65 (range 49-90) years were included in the study, and were examined in the office for signs and symptoms. A digital rectal examination was performed, and if indicated, the patients were sent to the laboratory for a PSA test. If the attending clinician subsequently decided that a patient should have a prostate biopsy, the patient underwent an EIS bioimpedance measurement prior to the biopsy.

\section{Measurement of bioimpedance}

The parameter used by the EIS is the delta of the electrical resistance values between the pathway value for left foot to right foot (anode to cathode) minus the pathway value for right foot to left foot (cathode to anode), expressed in numeric form on a scale from 0 to 100 .

The EIS is a programmable electromedical system comprising a USB plug and hardware including an interface box, disposable electrodes, reusable plates, and reusable cables, with software installed on a computer. The system 
uses bioimpedance in bipolar mode with direct current, and measures the electrical conductivity of 11 pathways of the body, each recorded twice from anode to cathode and then from cathode to anode. The pathways are measured between four large tactile reusable electrodes $\left(>270 \mathrm{~cm}^{2}\right)$ placed on the palms of the hands and soles of the feet, and smaller disposable electrodes $\left(15 \mathrm{~cm}^{2}\right)$ placed on the left and right forehead. Electrode polarization does not affect the bioimpedance measurement, ${ }^{11}$ and the transmission of the current from the electrode to the hardware is performed by chronoamperometry. ${ }^{12}$

\section{EIS and electrical conductivity/chronoamperometry} With direct current, the plasma membrane acts as an insulator and the current is not able to penetrate the cell, so most of the current flows around the cell and therefore in the interstitial fluid. ${ }^{13}$ Analysis of the direct current at the cathode and anode in electrolytic solution is performed at both the anode and the cathode. ${ }^{13}$

\section{Analysis at the cathode}

The electrochemical reaction at the cathode is:

$$
2 \mathrm{H}_{2} \mathrm{O}+2 \mathrm{e}=\mathrm{H} 2(\text { gas })+2 \mathrm{OH}-(\text { base })
$$

\section{Analysis at the anode}

The electrochemical reaction for water at the anode is:

$$
2 \mathrm{H}_{2} \mathrm{O}=\mathrm{O}_{2}(\text { gas })+4 \mathrm{H}++4 \mathrm{e}-(\text { acid })
$$

\section{Parameters analyzed}

Analysis of the specificity and sensitivity of the data was done in accordance with the biopsy results. Receiver-operating characteristic curves were constructed for the PSA value and tissue diagnosis and for the EIS data and tissue diagnosis, and algorithms were constructed for the PSA-EIS data and tissue diagnosis. Raw analysis of the EIS data as an adjunct to the PSA value was also undertaken.

\section{Statistical analysis}

Statistical analysis of the results was performed using MedCalc software. The number of patients needed for the study was calculated to be 50 on the basis of $\alpha=5 \%$, at $80 \%$ power $=\mathrm{F}(\Delta, \mathrm{N}$, variability $\mathrm{DS})$, taking into account the judgment criteria $\Delta$ at approximately 50 DS (5\% error).

A $P$ value of $<0.005$ was accepted as being statistically significant.

\section{Results}

The results of this investigation showed that PSA had a sensitivity of $73.9 \%$ and a specificity of $51.9 \%$ for the detection of prostate cancer using a cutoff value $>4$ (Figure 1) and a sensitivity of $52.2 \%$ and specificity of $81.5 \%$ using a cutoff value $\geq 5.7(P=0.03)$ (Figure 2 ).

The delta for the electrical conductivity (DE) of the pathway from left foot to right foot had a sensitivity of $62.5 \%$ and a specificity of $85.2 \%$ using a cutoff value $\leq-5$ $(P=0.0001)$ (Figure 3).

The algorithms All (PSA Value multiplied by the delta value for the electrical conductivity) incorporating the delta of electrical conductivity and PSA value had a sensitivity of $91.5 \%$ and a specificity of $59.3 \%$ using a cutoff value $\leq-10.52(P=0.0003)$ (Figure 4$)$.

Raw analysis of the EIS data as an adjunct to the PSA value (Tables 1 and 2).

\section{Discussion}

Although strategies for primary prevention of prostate cancer are being tested, to date none are known to be effective. The most common strategy for reducing the burden of prostate cancer is screening, but this remains controversial. Urologists are often faced with the dilemma of elevated PSA in young patients. This is a difficult situation, because these patients often do not want to undergo a prostate biopsy and fear a diagnosis of prostate cancer due to the potential side effects

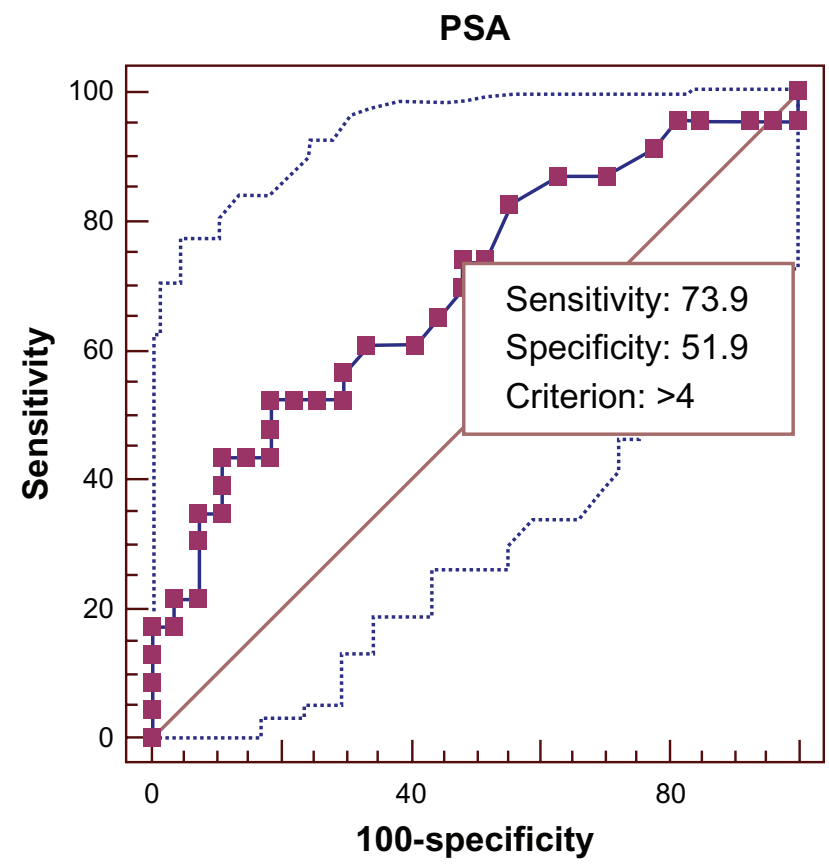

Figure I Receiver-operating characteristic curve: PSA cutoff value $>4 \mathrm{ng} / \mathrm{mL}$ comparing positive biopsy group versus negative biopsy group. 


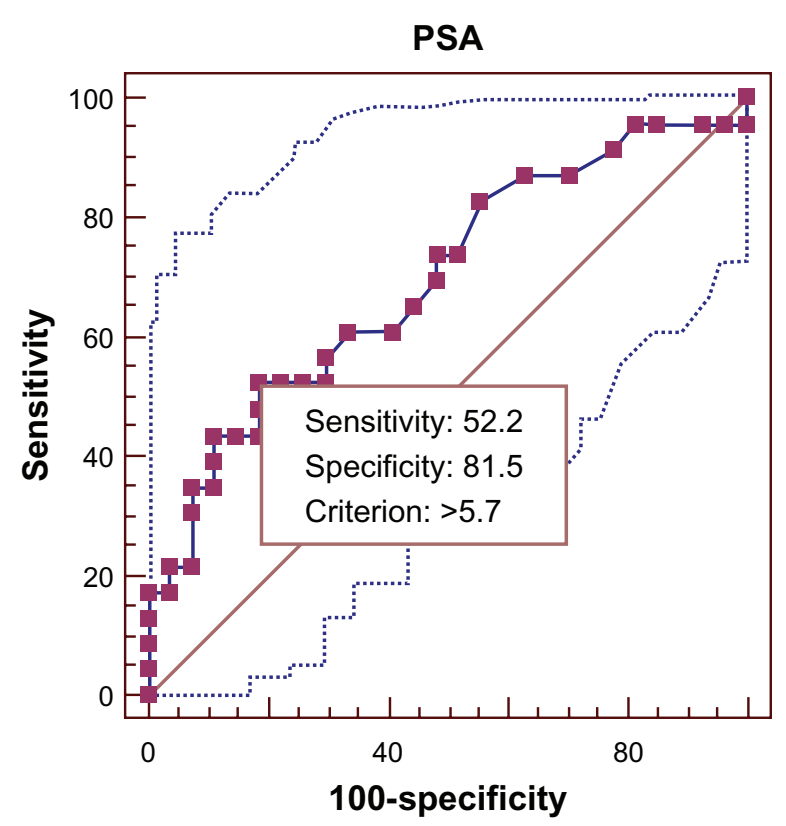

ROC curve

\begin{tabular}{|l|l|}
\hline Variable & PSA \\
\hline Classification variable & diagnosis \\
\hline
\end{tabular}

\begin{tabular}{|l|l|r|}
\hline Sample size & & 50 \\
\hline Positive group: & DIAGNOSIS $=1$ & 23 \\
\hline Negative group: & DIAGNOSIS $=0$ & 27 \\
\hline
\end{tabular}

\begin{tabular}{|l|r|}
\hline Standard Error & \\
\hdashline $95 \%$ Confidence interval & \\
\hdashline b statistic & 0.0763 \\
\hline Significance level P (Area $=0.5)$ & 0.548 to 0.816 \\
\hline
\end{tabular}

aDeLong et al., 1988

'Binomial exact

Figure 2 Receiver-operating characteristic curve and data analysis: PSA cutoff value $>5.7 \mathrm{ng} / \mathrm{mL}$ comparing positive biopsy group versus negative biopsy group.

of treatment, including the possibility of urinary incontinence and erectile dysfunction.

Criteria for a clinically useful screening test are:

- The disease must constitute a serious public health problem

- The disease must be able to be diagnosed during an asymptomatic, localized phase

- The screening test must have an appropriate sensitivity, specificity, and predictive value

\section{Delta}

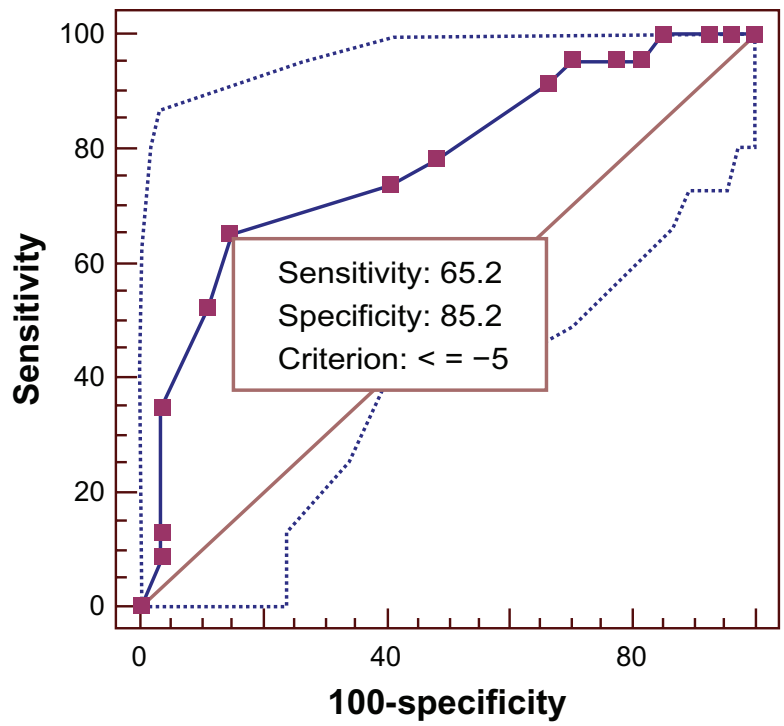

- The potential for cure must be greater in patients detected by screening

- Improved outcomes related to screening must be shown and, after these criteria are satisfied, the cost-effectiveness of the screening program must also be justified. ${ }^{14}$

The importance of prostate cancer as a public health problem and the fact that it can be diagnosed during an asymptomatic, localized stage easily satisfy using PSA and digital rectal examination as screening tools for the first two

ROC curve
\begin{tabular}{|l|l|}
\hline Variable & delta \\
\hline Classification variable & diagnosis \\
\hline
\end{tabular}

\begin{tabular}{|l|l|r|}
\hline Sample size & & 50 \\
\hline Positive group: & DIAGNOSIS $=1$ & 23 \\
\hline Negative group: & DIAGNOSIS $=0$ & 27 \\
\hline
\end{tabular}

\begin{tabular}{|l|l|}
\hline Disease prevalence (\%) & 46 \\
\hline
\end{tabular}

\begin{tabular}{l|r|}
\hline Area under the ROC curve (AUC) & 0.775 \\
\hline Standard Error & 0.0676 \\
\hline $95 \%$ Confidence interval & \\
\hline Z statistic & 0.634 to 0.881 \\
\hline Significance level P (Area = 0.5) & 4.062 \\
\hline aDeLong et al., 1988 & $<0.0001$ \\
\hline & \\
& 'Binomial exact
\end{tabular}

Figure 3 Receiver-operating characteristic curve and data analysis: Delta Electrical conductivity (DE) cutoff value $\leq-5$ comparing positive biopsy group versus negative biopsy group.

*Delta of the electrical conductivity between the pathway conductivity ieft foot- right foot minus the pathway conductivity right foot-left foot expressed in numeric values from 0 - I00. 


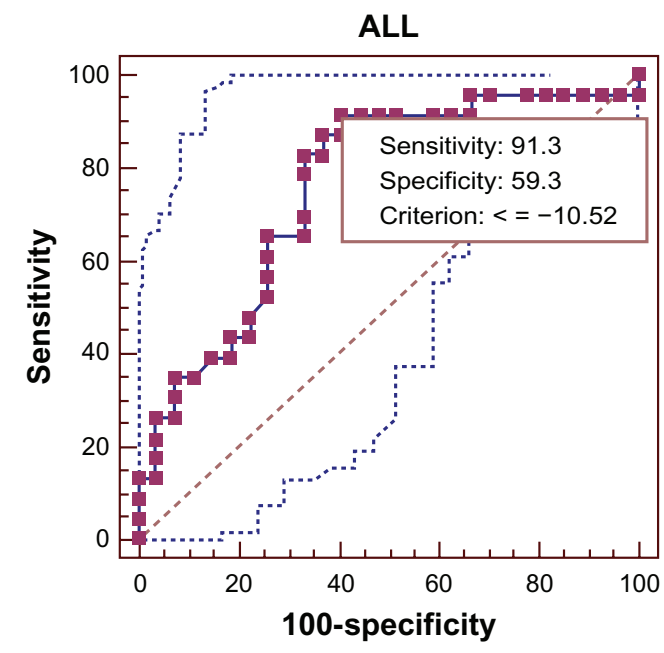

ROC curve

\begin{tabular}{l|l|r|}
\hline Variable & ALL & \\
\cline { 1 - 2 } Classification variable & diagnosis & \\
\hline Sample size & \multicolumn{2}{|l|}{} \\
\hdashline Positive group: & DIAGNOSIS $=1$ & 23 \\
\hdashline Negative group: & DIAGNOSIS $=0$ & 27 \\
\hline
\end{tabular}

\begin{tabular}{|l|l|}
\hline Area under the ROC curve (AUC) & 0.757 \\
\hline
\end{tabular}

\begin{tabular}{lr} 
Standard Errora & 0.0706 \\
\hline $95 \%$ Confidence interval & \\
\hline$z$ & 0.615 to 0.867 \\
\hline
\end{tabular}

\begin{tabular}{l|r}
$95 \%$ Confidence interval & 0.615 to 0.867 \\
\hline$z$ statistic & 3.636 \\
\hline
\end{tabular}

Significance level P (Area $=0.5$ )

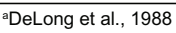

bBinomial exact

Figure 4 Receiver-operating characteristic curve and data analysis: Test All cutoff value $\leq-10.52$ comparing positive biopsy group versus negative biopsy group. *ALL Delta of the electrical conductivity value multiplied by the PSA value.

of the above-listed criteria, but there are no clear answers for the rest.

An autopsy study in Detroit men found previously undiagnosed prostate cancer in $30 \%$ of men in the age range 20-40 years, and in more than one half of men older than 50 years. The prevalence of these unsuspected prostate cancers is consistently estimated to be about $33 \%{ }^{15}$ These high rates of unsuspected prostate cancers are in sharp contrast with the $3.64 \%$ estimated lifetime risk of dying from prostate cancer, as well as the $1.8 \%$ detection rate

Table I Analysis of the positive patients group

\begin{tabular}{|c|c|c|c|c|c|c|c|c|c|}
\hline $\begin{array}{l}\text { Patient } \\
\text { code }\end{array}$ & Age & $\begin{array}{l}\text { Positivie test }=\mathrm{I} \\
\text { Negative test }=0\end{array}$ & $\begin{array}{l}\text { Delta } \\
\text { DE }\end{array}$ & PSA & $\begin{array}{l}\text { ALL } \\
\text { [DE-PSA] } \\
<-10.52\end{array}$ & $\begin{array}{l}\text { Delta } \\
\text { DE } \leq-0.5\end{array}$ & PSA $\geq-4$ & $\begin{array}{l}\text { ALL } \\
{[D E-P S A]} \\
\leq 10.52\end{array}$ & $\begin{array}{l}\text { Current } \\
\text { treatment }\end{array}$ \\
\hline IZH05 & 57 & I & -6 & 200.2 & -1201.2 & $x$ & $x$ & $x$ & No treatment \\
\hline IZMI3 & 90 & I & 2 & 45 & 90 & & $x$ & & Diuretics/furosemide \\
\hline IZDI9 & 67 & I & -9 & 26.0 & -234 & $x$ & $x$ & $x$ & $\mathrm{ACE}$ \\
\hline IZL06 & 79 & I & -4 & 4.4 & -17.6 & & $x$ & $x$ & No treatment \\
\hline $1 \mathrm{Zd} 26$ & 62 & I & -3 & 19 & -57 & & $x$ & $x$ & Diuretics/furosemide \\
\hline IZSI9 & 66 & I & -8 & 3.1 & -24.8 & $x$ & & $x$ & No treatment \\
\hline IZTI5 & 64 & I & -8 & II & -88 & $x$ & $x$ & $x$ & No treatment \\
\hline |ZA3| & 69 & I & -6 & 3.0 & -18.06 & $x$ & & $x$ & No treatment \\
\hline IZLOI & 89 & I & -6 & 4.1 & -24.6 & $x$ & $x$ & $x$ & ACE, insulin NPH \\
\hline IZB08 & 76 & I & -10 & 3.5 & -35 & $x$ & & $x$ & ACE, diuretics \\
\hline IZC30 & 56 & I & -8 & 3.5 & -28 & $x$ & & $x$ & No treatment \\
\hline IZAIO & 52 & I & -8 & 3.3 & -26.4 & $x$ & & $x$ & Simvastatin, omeprazole \\
\hline IZF06 & 84 & I & -2 & 7.5 & -15 & & $x$ & $x$ & ACE, ranitidine \\
\hline IZSO4 & 80 & I & -4 & 14 & -56 & & $x$ & $x$ & Diuretics, ACE \\
\hline IZF03 & 57 & I & -8 & 2.3 & -18.4 & $x$ & & $x$ & $\begin{array}{l}\text { Angiotensin II antagonists, } \\
\text { Crestor }\end{array}$ \\
\hline IZSO2 & 62 & I & -5 & 14.0 & -70 & $x$ & $x$ & $x$ & No treatment \\
\hline$|Z x| 7$ & 68 & I & -1 & 4.9 & -4.9 & & $x$ & & $\mathrm{ACE}$, diuretics \\
\hline IZS28 & 76 & I & -6 & 319 & -1914 & $x$ & $x$ & $x$ & $\begin{array}{l}\text { Metformin ACE, } \\
\text { Diuretics }\end{array}$ \\
\hline IZD22 & 74 & I & -10 & 6.5 & -65 & $x$ & $x$ & $x$ & ACE, simvastatin \\
\hline IZR25 & 50 & I & -2 & 5.26 & -10.52 & & $x$ & $x$ & No treatment \\
\hline IZF28 & 71 & I & -5 & 6.0 & -30 & $x$ & $x$ & $x$ & No treatment \\
\hline IZMII & 59 & I & -2 & 9 & -18 & & $x$ & $x$ & Alpha blockers \\
\hline IWR28 & 55 & 1 & -5 & 4.2 & -21 & $\mathrm{X}$ & $x$ & $x$ & ACE, selozok \\
\hline
\end{tabular}

Note: $\mathrm{X}=$ Right results in reference to the biopsies. 
Table 2 Analysis of the negative patients group

\begin{tabular}{|c|c|c|c|c|c|c|c|c|c|}
\hline $\begin{array}{l}\text { Patient } \\
\text { code }\end{array}$ & Age & $\begin{array}{l}\text { Positive test }=1 \\
\text { Negative test }=0\end{array}$ & $\begin{array}{l}\text { Delta } \\
\text { DE }\end{array}$ & PSA & $\begin{array}{l}\text { All } \\
\text { (DE-PSA) } \\
\leq-10.52\end{array}$ & $\begin{array}{l}\text { Delta } \\
\text { DE } \leq-5\end{array}$ & PSA $>4$ & $\begin{array}{l}\text { All } \\
\text { (DE-PSA) } \\
\leq-10.52\end{array}$ & Correct treatment \\
\hline IZE22 & 55 & 0 & -3 & 3.2 & -9.6 & $\mathrm{X}$ & $x$ & $\mathrm{X}$ & No treatment \\
\hline IZCOI & 57 & 0 & 1 & 3.3 & 3.3 & $x$ & $x$ & $x$ & $\begin{array}{l}\text { Insulin, corticosteroid, ACE, } \\
\text { Diuretics, metformin }\end{array}$ \\
\hline IZLIO & 73 & 0 & -4 & 16 & -64 & $\mathrm{X}$ & & & No treatment \\
\hline IZBII & 65 & 0 & 0 & 2.6 & 0 & $x$ & $x$ & $\mathrm{X}$ & No treatment \\
\hline IZd08 & 64 & 0 & 6 & 4.9 & 29.4 & $x$ & & $x$ & No treatment \\
\hline IZDII & 60 & 0 & -6 & 4.4 & -26.4 & & & & ACE, imipcamin, ranitidine \\
\hline IZd30 & 64 & 0 & -4 & 4.7 & -18.8 & $\mathrm{X}$ & & & No treatment \\
\hline IZC20 & 68 & 0 & 3 & 5.52 & 16.56 & $\mathrm{x}$ & & $\mathrm{X}$ & $\mathrm{ACE}$ \\
\hline IZP09 & 81 & 0 & -6 & 5.61 & -33.66 & & & & $\begin{array}{l}\text { Angiotensin II inhibitor, } \\
\text { Simvastatin }\end{array}$ \\
\hline IZL20 & 76 & 0 & 5 & 2.8 & 14 & $\mathrm{X}$ & $X$ & $x$ & $\mathrm{ACE}$ \\
\hline IZA04 & 62 & 0 & -2 & 3.1 & -6.2 & $\mathrm{x}$ & $x$ & $x$ & No treatment \\
\hline$|Z d| 8$ & 63 & 0 & -2 & 2.7 & -5.4 & $x$ & $x$ & $x$ & No treatment \\
\hline |ZG2| & 67 & 0 & 0 & 3.2 & 0 & $x$ & $x$ & $x$ & Simvastatin, bromazepan \\
\hline IZBOI & 71 & 0 & -4 & 4.7 & -18.8 & $x$ & & & Chondroitin \\
\hline IZA26 & 77 & 0 & -5 & 7.0 & -35 & $x$ & & $x$ & Cefalexin \\
\hline IZFII & 69 & 0 & -4 & 3.0 & -12 & $x$ & $\mathrm{X}$ & $x$ & Digoxin, ACE \\
\hline IZA09 & 53 & 0 & -10 & 4.2 & -42 & & & & No treatment \\
\hline IZDII & 54 & 0 & -1 & 3.3 & -3.3 & $\mathrm{x}$ & $\mathrm{X}$ & $\mathrm{X}$ & no treatment \\
\hline IZdI8 & 68 & 0 & -4 & 7.1 & -28.4 & $x$ & & & No treatment \\
\hline IZLII & 73 & 0 & -4 & 4 & -16 & $x$ & $\mathrm{X}$ & & $\mathrm{ACE}$ \\
\hline IZCII & 69 & 0 & 3 & 5.7 & 17.1 & $x$ & & $x$ & No treatment \\
\hline IZGI3 & 62 & 0 & -2 & 3.1 & -6.2 & $x$ & $\mathrm{x}$ & $x$ & No treatment \\
\hline IZI28 & 61 & 0 & -2 & 2.9 & -5.8 & $x$ & $x$ & $x$ & Omeprazol \\
\hline IZDIO & 69 & 0 & -4 & 23 & -92 & $x$ & & & $\mathrm{ACE}$ \\
\hline IZL|4 & 62 & 0 & 2 & 10 & 20 & $x$ & & $x$ & $\begin{array}{l}\text { Angiotensin II inhibitor, } \\
\text { Ranitidine }\end{array}$ \\
\hline IZM03 & 53 & 0 & -3 & 2.8 & -8.4 & $\mathrm{X}$ & $x$ & $x$ & Angiotensin II inhibitor \\
\hline |ZA3 | & 49 & 0 & -2 & 3.5 & -7 & $\mathrm{X}$ & $x$ & $\mathrm{x}$ & Simvastatin, omeprazole \\
\hline
\end{tabular}

Note: $\mathrm{X}=$ Right results in reference to the biopsies.

of prostate carcinoma in pooled data from a recent metaanalysis. Once regional lymph node involvement is present, the probability of death from prostate cancer is $70 \%$, and $50 \%$ of men with regional lymph node involvement will die in two years. Prostate cancer is a real risk for the aging man, because almost $10 \%$ of men older than 50 years are likely to develop clinically serious disease. Therefore, it should be detected at an early stage, ${ }^{16}$ and to improve early detection rates it is necessary to increase the sensitivity of the screening tests used.

In the current study, the sensitivities of PSA and digital rectal examination screening were $72.1 \%$ and $53.2 \%$, respectively. Reducing the PSA cutoff point from $4 \mathrm{ng} / \mathrm{mL}$ to $3 \mathrm{ng} / \mathrm{mL}$ can increase the sensitivity, but doing so will reduce further the positive predictive value. ${ }^{16}$ It is also well known that PSA values for prostate cancer and benign prostate hyperplasia overlap considerably. Between 21\% and $47 \%$ of men with histologically proven benign prostate hyperplasia have PSA levels $>4 \mathrm{ng} / \mathrm{mL}$, and up to $43 \%$ of men with prostate cancer will have a PSA level $<4 \mathrm{ng} / \mathrm{mL}$. This overlap makes it harder to differentiate benign prostate hyperplasia from prostate carcinoma in the absence of a biopsy. PSA values also increase with age. ${ }^{17}$

With prostate cancer, the risk of overdiagnosis is likely to be much more relevant than with other types of cancer screening, because in men aged 55-60 years, the risk of death from other causes is considerably higher than that from prostate cancer. It is estimated that for every patient who dies of prostate cancer, at least 380 others have prostate cancer that cannot be detected clinically. ${ }^{18}$ The treatment of prostate cancer consists of radical surgery or radiotherapy, and both can cause complications, including a high frequency of sexual impotence, rectal and urinary dysfunction, as well and a mortality risk of $1 \%-2 \%$. 
The EIS technique, when used as a screening test, meets the requirements of the World Health Organization guidelines stating that a screening test should be acceptable to the population, be rapidly performed (no more than two minutes), cost-effective and noninvasive, and that the total cost of finding a case should be economically balanced in relation to medical expenditure as a whole.

In the present study, the positive predictive values for PSA and digital rectal examination were about $25 \%$ and $18 \%$, respectively, which means one of four or five biopsies is unnecessary. Unnecessary biopsies can lead to multiple invasive procedures, anxiety for the patient, procedurerelated complications, and a high cost of health care delivery. To reduce further unnecessary procedures, a meta-analysis ${ }^{19}$ has proposed use of transrectal ultrasonography in patients with elevated PSA levels but benign digital rectal examination findings, followed by biopsy only of visible abnormal lesions. If findings on digital rectal examination are abnormal, the patient should undergo transrectal ultrasound and then a biopsy, regardless of the PSA value. A small, organ-confined prostate tumor has an estimated doubling time of about four years. Thus, it will take about 15 years for a $1 \mathrm{~mL}$ tumor to become life-threatening. It would be more straightforward to say that until there is evidence for effectiveness of screening in decreasing mortality, based on these growth rates, a man would need to have at least 15 years of remaining life expectancy to benefit from PSA screening.

In the US, there are 30.8 million men older than 50 years of age who qualify for PSA screening..$^{20}$ According to our calculations, based on fees charged at one urologist's office in New Jersey, the cost of PSA screening in all these men would be $\$ 3.1$ billion. Of this population, $10.1 \%$ (approximately 3.1 million men) will have PSA levels $>4 \mathrm{ng} / \mathrm{mL}$. Assuming all patients with abnormal PSA levels are referred to a urologist for further evaluation, the first visit will cost \$275 (for the office visit, urine analysis, and culture). The second visit will involve sonography of the prostate, bladder, pelvis, and renal organs, as well as guided needle biopsy, which can cost $\$ 2170$ per patient. Therefore, the total cost of these two visits would exceed $\$ 7.6$ billion for 3.1 million men. Of 3.1 million biopsies performed, 75\%, ie, 2.3 million will be negative for prostate carcinoma.

In our study, the EIS delta parameter had a good specificity of $85.2 \%$ and a sensitivity of $65.2 \%$, although we noted that for the eight positive patients, none of which were identified by the delta parameter, four are undergoing diuretic treatment and one is receiving an alpha-blocker treatment.

\section{Conclusion}

Using the EIS system as an independent predictor of prostate cancer, it has a good specificity of $85.2 \%$. However, the sensitivity of $62.5 \%$ will be a problem. Using the PSA reference of $\geq 4.1 \mathrm{ng} / \mathrm{mL}$, adjunctive use of the EIS system measuring bioimpedance and chronoamperometry could raise the sensitivity from $73.9 \%$ to $91.5 \%$ and the specificity from $51.9 \%$ to $59.3 \%$ in prostate cancer screening. To our knowledge, this is the first study using a noninvasive bioimpedance-chronoamperometry technique for prostate cancer screening. A longitudinal study is now under way to confirm our findings.

\section{Acknowledgments}

Thanks are extended to all the people who contributed to this investigation, Dr Daniel Ianni Filho for collecting the data for this study, Labclin Laboratorio de Análises Clínicas for PSA testing, CEAP Hospital for the biopsies, and LapMed for analysis of the biopsies.

\section{Disclosure}

This study was sponsored by LD Technology, Miami, FL. Otherwise; the author reports no conflicts of interest in this work.

\section{References}

1. Wingo PA, Landis S, Ries LA. An adjustment of the 1997 estimate for new prostate cancer cases. CA Cancer J Clin. 1997;47: 239-242.

2. Parker SL, Tong T, Bolden S, Wingo PA. Cancer statistics, 1997. CA Cancer J Clin. 1997; 47:5-27.

3. US Bureau of the Census, Population Division. Resident population of the United States: Estimates, by age and sex. Washington, DC: US Bureau of the Census, Population Division, release PPL-91. Available at: http:// www.census.gov/population/estimates/nation/intfile2-1.txt. Accessed March 21, 2011.

4. Catalona WJ, Smith DS, Ratliff TL. Measurement of prostate specific antigen in serum as a screening test for prostate cancer. $N$ Engl J Med. 1991;324:1156-1161

5. Catalona WJ, Richie JP, Ahmann FR, et al. Comparison of digital rectal examination and serum prostate specific antigen in the early detection of prostate cancer: Results of a multicenter clinical trial of 6,630 men. J Urol. 1994;151:1283-1290.

6. Arcangeli CG, Ornstein DK, Keetch DW, Andriole GL. Prostate specific antigen as a screening test for prostate cancer. The United States experience. Urol Clin North Am. 1997;24:299-306.

7. Ko HW, Smith DG, Skura JP. In vitro measurements of brain edema with the magnetic bio-impedance method. Presented at the annual conference of the IEEE Engineering in Medicine and Biology Society, Amsterdam, The Netherlands, October 31-November 3, 1996.

8. Kimura S, Morimoto T, Uyama T, Monden Y, Kinouchi Y Iritani T. Application of electrical impedance analysis for diagnosis of a pulmonary mass. Chest. 1994;105:1679-1682.

9. Halter RJ, Schned A, Heaney J, Hartov A, Schutz S, Paulsen KD. Electrical impedance spectroscopy of benign and malignant prostatic tissues. $J$ Urol. 2008;179:1580-1586. 
10. Mamalakis G, Kafatos A, Kalogeropoulos N, Andrikopoulos N, Daskalopulos G, Kranidis A. Prostate cancer vs hyperplasia: relationships with prostatic and adipose tissue fatty acid composition. Prostaglandins Leukot Essent Fatty Acids. 2002 May-Jun;66 (5-6):467-477. Cole KS, Li CL, Bak AF. Electrical analogues for tissues. Exp Neurol. 1969;24:459-473.

11. Grimmes S, Martinsen ØG. Electrolytics In Bioimpedance and Bioelectricity Basics. San Diego, CA: Academic Press; 2000.

12. Cottrell FG. Application to the Cottrell equation to chronoamperometry. Z Physik Chem. 1902;42:385.

13. Gabriel S, Lau RW, Gabriel C. The dielectric properties of biological tissues: III. Parametric models for the dielectric spectrum of tissues. Phys Med Biol. 1966;41:2271-2293.

14. Svetec D, Thompson IM. PSA screening - current controversy. Ann Oncol. 1998;9:1283-1288.

15. Godley PA. Prostate cancer screening: Promise and peril - a review. Cancer Detect Prev. 1999;23:316-324.
16. Scardino PT. Early detection of prostate cancer. Urol Clin North Am. 1989;16:635-655.

17. Cochran WG. Sampling Techniques. 3rd ed. New York, NY: John Wiley \& Sons; 1977.

18. Zappa M, Ciatto S, Bonardi R, Mazzotta A. Overdiagnosis of prostate carcinoma by screening: An estimate based on the results of the Florence screening pilot study. Ann Oncol. 1998;9:1297-1300.

19. Alan W, Partin MD, Michael W, et al. Combination of Prostate-Specific Antigen, Clinical Stage, and Gleason Score to Predict Pathological Stage of Localized Prostate Cancer. JAMA. May 14,1997;277(18): $1445-1451$.

20. Kishor Mistry, Greg Cable. Meta-Analysis of Prostate-Specific Antigen and Digital Rectal Examination as Screening Tests for Prostate Carcinoma. The Journal of the American Board of Family Practice. 2003;16:95-101.

\section{Publish your work in this journal}

Cancer Management and Research is an international, peer-reviewed open access journal focusing on cancer research and the optimal use of preventative and integrated treatment interventions to achieve improved outcomes, enhanced survival and quality of life for the cancer patient. The journal welcomes original research, clinical \& epidemiological studies, reviews \& evaluations, guidelines, expert opinion \& commentary, case reports \& extended reports. The manuscript management system is completely online and includes a very quick and fair peerreview system, which is all easy to use. Visit http://www.dovepress.com/ testimonials.php to read real quotes from published authors. 